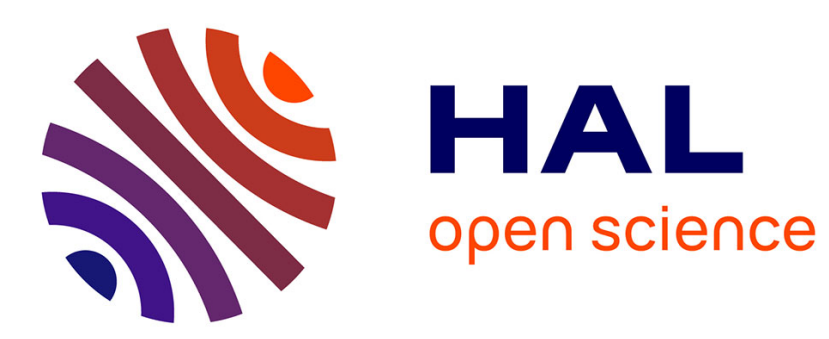

\title{
Itinerant metamagnetism in TiBe2
}

E.P. Wohlfarth

\section{- To cite this version:}

E.P. Wohlfarth. Itinerant metamagnetism in TiBe2. Journal de Physique Lettres, 1980, 41 (23), pp.563-565. 10.1051/jphyslet:019800041023056300 . jpa-00231847

\section{HAL Id: jpa-00231847 https://hal.science/jpa-00231847}

Submitted on 1 Jan 1980

HAL is a multi-disciplinary open access archive for the deposit and dissemination of scientific research documents, whether they are published or not. The documents may come from teaching and research institutions in France or abroad, or from public or private research centers.
L'archive ouverte pluridisciplinaire HAL, est destinée au dépôt et à la diffusion de documents scientifiques de niveau recherche, publiés ou non, émanant des établissements d'enseignement et de recherche français ou étrangers, des laboratoires publics ou privés. 
Classification

Physics Abstracts

$75.30-75.50$

\title{
Itinerant metamagnetism in $\mathbf{T i B e}_{2}$
}

\author{
E. P. Wohlfarth \\ Department of Mathematics, Imperial College, London SW7 2BZ, U.K.
}

(Reçu le 2 septembre 1980, accepté le 7 octobre 1980)

Résumé. - On discute les mesures de Monod, Felner, Chouteau et Shaltiel [1] de l'aimantation du composé défini $\mathrm{TiBe}_{2}$ sous champs intenses en termes d'une transition métamagnétique sous champs de $5 \mathrm{~T}$ environ.

\begin{abstract}
The high field magnetization data of Monod, Felner, Chouteau and Shaltiel [1] on $\mathrm{TiBe}_{2}$ are discussed in terms of a metamagnetic transition in fields about $5 \mathrm{~T}$.
\end{abstract}

Monod et al. [1] have measured the high field magnetization of the cubic Laves phase compound $\mathrm{TiBe}_{2}$ and observed a positive deviation from the low field linear dependence of this magnetization at fields above $3 \mathrm{~T}$. At fields above about $7 \mathrm{~T}$ the corresponding curves begin to deviate towards the field axis. It is proposed here that this set of phenomena as well as other related results which will be summarized below are a manifestation of itinerant metamagnetism in this compound. $\mathrm{TiBe}_{2}$ was at first [2] thought to be an itinerant antiferromagnet. It now appears, however, that it is in fact a strongly exchange enhanced paramagnet similar to $\mathrm{Pd}$ and $\mathrm{YCo}_{2}$. The antiferromagnetism was felt to arise since the magnetic susceptibility has a maximum at about $10 \mathrm{~K}$. The absence of this spin ordering is deduced from neutron [3], specific heat [4] and ESR [5] data. Metamagnetism, i.e. a first order magnetic process, was predicted [6] to occur in $\mathrm{TiBe}_{2}$ prior to the measurements [1], but at that time the metamagnetic process was suggested to occur from an antiferromagnetic to a ferromagnetic state in a high field, as first proposed in [7]. However, as first proposed in [8], such an effect may equally well occur from a paramagnetic to a ferromagnetic state. Both phenomena have more recently been observed, as summarized in [6] and [9], and $\mathrm{TiBe}_{2}$ thus joins an interesting list of itinerant metamagnets. The prediction in [6] was made since $\mathrm{TiBe}_{2}$ was shown in [10] to transform into an itinerant ferromagnet when substituting more than about $6 \% \mathrm{Be}$ by $\mathrm{Cu}$; this substitution was felt [6] to lead to an internal magnetic field due to local environment effects on the magnetic moments which reside on the $\mathrm{Ti}$ atoms [11]. This internal field may lead to metamagnetism as first observed with Gd doped
$\mathrm{YCo}_{2}$ [12], [6], and more recently with $\mathrm{Gd}$ doped $\mathrm{Y}_{4} \mathrm{Co}_{3}$ [13] and other materials [9]. The process should thus, it was argued, also occur in high external fields. The local environment effects thus envisaged in $\mathrm{Cu}$ doped $\mathrm{TiBe}_{2}$ are not at all clear and will have to be studied further, both experimentally and theoretically, since this set of phenomena is interesting enough to deserve further investigation.

It is now proposed to enlarge slightly on the above discussion, in particular the detailed findings of [1] : Itinerant metamagnetism was shown to be most likely [8] if the low field susceptibility has a temperature maximum. At that time Pd was thus regarded as a good candidate but it now appears that the critical magnetic field is too high. Nevertheless, the occurrence of such maxima continues to point to this phenomenon in both $\mathrm{YCo}_{2}$ [12] and $\mathrm{TiBe}_{2}$ [2]. The critical fields may be estimated from the data tabulated in [1]. Using a Landau free energy expansion

$$
F=\frac{1}{2} A M^{2}+\frac{1}{4} B M^{4}-H M, \quad B<0,
$$

two critical fields may be defined [6] : $H_{\mathrm{c}}$ is the field where $\partial^{2} F / \partial M^{2}=0$ and $H_{c}^{*}$ where

$$
F\left[M\left(H_{\mathrm{c}}^{*}\right)\right]=F[0]=0,
$$

giving

$$
\left.\begin{array}{rl}
H_{\mathrm{c}} & =(2 / 3 \sqrt{3})\left(A^{3} /|B|\right)^{1 / 2} \\
H_{\mathrm{c}}^{*} & =(1 / \sqrt{2}) H_{\mathrm{c}}
\end{array}\right\}
$$

The tabulation in [1] leads to the following values of $H_{\mathrm{c}}^{*}$ :

$\mathrm{Pd}: 110 \mathrm{~T} ; \mathrm{YCo}_{2}: 17 \mathrm{~T} ; \mathrm{TiBe}_{2}: 5.8 \mathrm{~T}$. 
The «low » value for $\mathrm{YCo}_{2}$ is in disagreement with earlier estimates [12], [14] but the value for $\mathrm{TiBe}_{2}$ lies in the centre of the anomalous increase of $M$ observed in [1]. Of course, this increase is not sharp but spread over about $3 \mathrm{~T}$ and this effect will be briefly discussed below, again in terms of local environment effects. Nevertheless, this «low » value of $H_{\mathrm{c}}^{*}$ for $\mathrm{TiBe}_{2}$ makes this substance a more ideal itinerant metamagnet than $\mathrm{Pd}$ or $\mathrm{YCo}_{2}$. All three substances have susceptibility maxima in line with theory [8]. Such maxima may occur if the density of states curve has a local minimum or dip at the Fermi energy. Precisely this result was obtained in a band calculation for $\mathrm{TiBe}_{2}$ [15]. However, susceptibility maxima may also arise for other reasons, a case in point being the cubic material $\mathrm{TiH}_{2}$ ! Here such a maximum occurs at $300 \mathrm{~K} \mathrm{[16]} \mathrm{and} \mathrm{this} \mathrm{was} \mathrm{for} \mathrm{many} \mathrm{years} \mathrm{regarded}$ as an indication of antiferromagnetism (I was myself guilty of this heresy [17]). It is now clear, as shown by Ducastelle et al. [16] and Gupta [18], that an electronically driven tetragonal distortion at this temperature gives rise to the maximum and this possibility needs to be kept in mind also for $\mathrm{TiBe}_{2}$ and perhaps elsewhere.

Other features found in [1] and stressed there as particularly interesting include the low value of the magnetization at high fields compared to the value derived from the Curie-Weiss constant. This is, however, completely in line with the itinerant electron model : Above the critical field the material is in effect a "weak itinerant ferromagnet " and here the ratio of the Curie-Weiss to the saturation moment is always large [19]. In high fields the observed ratio tends very roughly to $1.64 / 0.2=8.2$, which would correspond [19] to an itinerant ferromagnet with Curie point about $30 \mathrm{~K}$. The Curie points of $\mathrm{Cu}$ doped $\mathrm{TiBe}_{2}$ increase with increasing copper content, reaching [10] $33 \mathrm{~K}$ for $\mathrm{Ti}\left(\mathrm{Be}_{0.75} \mathrm{Cu}_{0.25}\right)_{2}$. Hence this value of $30 \mathrm{~K}$, just crudely estimated, could be taken to be the limiting Curie temperature for the weak itinerant ferromagnet $\mathrm{TiBe}_{2}$ whose order is produced by very large internal or external fields. Monod et al. [1] also investigated several $\mathrm{Cu}$ doped $\mathrm{TiBe}_{2}$ specimens. For the sample $\mathrm{Ti}\left(\mathrm{Be}_{0.9} \mathrm{Cu}_{0.1}\right)_{2}$ the magnetization curve lies roughly a factor 2 below that reported in [10]. If this difference is real it might be a manifestation of the sensitivity of the transition to local environment effects, briefly discussed below. In the same way it may be possible to explain the fact that the magnetization curve of $\operatorname{Ti}\left(\mathrm{Be}_{0.99} \mathrm{Cu}_{0.01}\right)_{2}$ has an initial susceptibility below that of pure $\mathrm{TiBe}_{2}$, namely [1] $5.6 \times 10^{-3} \mathrm{emu} / \mathrm{mole}$ compared to $8.6 \times 10^{-3}$. The authors of [1] also point out that the magnetization curves for $\mathrm{TiBe}_{2}$ and $\mathrm{Ti}\left(\mathrm{Be}_{0.95} \mathrm{Cu}_{0.05}\right)_{2}$ tend to merge at fields above about $10 \mathrm{~T}$. Since this is already roughly $2 H_{c}^{*}$ it seems reasonable to expect this tendency of mutual approach of the magnetization curves in total (external + internal) fields of this order.

Reference has been made several times to the importance of local environment effects in this problem. It is envisaged that $\mathrm{TiBe}_{2}$ carries no moments in zero and low fields $<H_{\mathrm{c}}^{*}$. Adding copper atoms produces magnetically active $\mathrm{Ti}$ atoms [11], the magnetic distribution being rather well concentrated on these sites. However, it is clearly stated in [11] that further experiments are required to assess whether an average $\mathrm{Ti}$ site is the result of a uniform or a widely non-uniform environment of copper atoms. The effective internal fields would, in the second case, also vary sensitively, giving rise to the spread of the metamagnetic transition and to the differences of the magnetic results for different specimens of $\mathrm{Cu}$ doped $\mathrm{TiBe}_{2}$ alluded to earlier. The magnetic heterogeneities can, however, not be too severe since Arrott plots $\left(M^{2}\right.$ vs. $\left.H / M\right)$ have been found to be straight for $\operatorname{Ti}\left(\mathrm{Be}_{0.9} \mathrm{Cu}_{0.1}\right)_{2}$ [10]. On the other hand, such heterogeneities seem to show up in the high pressure data of $\mathrm{Chu}$ et al. [20].

Local environment effects can be assessed theoretically using modern approaches to the alloy problem [21]. What is at issue the effect of replacing $\mathrm{Be}$ by $\mathrm{Cu}$ atoms and the resulting effective fields on the magnetically active sites. The detailed mechanism is unknown and would require further theoretical considerations. Experimentally, it would be necessary to assess these fields and their distribution by several methods such as neutron scattering [11], Mössbauer, NMR, etc. The magnetic fields involved have been shown to be of the order of $5 \mathrm{~T}$, i.e. relatively low, and hence the sensitivity of the magnetic properties to these environmental effects must be considerable. The effects of heat treatment on these properties should thus also be investigated. I am grateful to the authors of [1], [5], [11] and [15] for their kindness in sending me preprints.

Note added in proof. - High field measurements on pure and $\mathrm{Cu}$ doped $\mathrm{TiBe}_{2}$ have also been reported by Acker et al. [22]. The results are similar to those of reference [1] and were interpreted in terms of exchange enhanced paramagnetism in all fields, in contrast to the present proposals. However, the Arrott plots for $\mathrm{TiBe}_{2}$ continue to curve in the highest fields applied (21.3 T), making it impossible to distinguish the two proposals. Furthermore, the $\chi$ versus $H$ maximum, here regarded as manifesting spread first order transitions, were proposed in [22] to follow from Fermi liquid theory, giving a term in $\chi$ going as $H^{2} \ln H$. The status of this term is, however, still completely uncertain, as is that of the $T^{2} \ln T$ term used in [22] to explain the susceptibility versus temperature maximum. 


\section{References}

[1] Monod, P., Felner, I., Chouteau, G. and Shaltiel, D., J. Physique Lett. 41 (1980) L-511.

[2] Matthias, B. T., Giorgi, A. L., Struebing, V. O. and Smith, J. L., J. Physique Lett. 39 (1978) L-441 ; see also SAJI, H., Yamadaya, T. and Asanuma, M., J. Phys. Soc. Japan 21 (1966) 255.

[3] Rakhecha, V. C., Felcher, G. P., Sinha, S. K., Smith, J. L. and Matthias, B. T., Solid State Commun. 33 (1980) 495.

[4] Stewart, G. R., Matthias, B. T., Giorgi, A. L., Szklarz, E. G. and Smith, J. L., Solid State Commun. 30 (1979) 709.

[5] Shaltiel, D., Monod, P. and Felner, I., Conf. Physics Trans. Metals, Leeds 1980, J. Physique Lett. 41 (1980) L-567.

[6] Wohlfarth, E. P., J. Magn. Mag. Mat. 20 (1980) 77.

[7] Wohlfarth, E. P., Phys. Lett. 4 (1963) 83.

[8] Wohlfarth, E. P. and Rhodes, P., Philos. Mag. 7 (1962) 1817.

[9] Gignoux, D., Givord, D., Laforest, J., Lemaire, R. and Molho, P., Conf. Physics Trans. Metals, Leeds 1980, to be published.

[10] Giorgi, A. L., Matthias, B. T., Stewart, G. R., Acker, F. and Smith, J. L., Solid State Commun. 32 (1979) 455.

[11] Felcher, G. P., Cable, J. W. and Smith, J. L., Phys. Rev. Lett. 45 (1980) 751.
[12] Bloch, D., Edwards, D. M., Shimizu, M. and Voiron, J., J. Phys. F 5 (1975) 1217.

[13] Gratz, E., Sechovsky, V., Wohlfarth, E. P. and KirchMAYr, H. R., J. Phys. F 10 (1980), to be published.

[14] Steiner, W., J. Magn. Mag. Mat. 14 (1979) 47.

[15] De Groot, R. A., Koelling, D. D. and Mueller, F. M., J. Phys. F 10 (1980) L-235; JARLBORG, T. and FreEMan, A. J., Phys. Rev. B (1980), to be published.

[16] Trzebiatowski, W. and Stalinski, B., Bull. Acad. Polon. Sci. (Cl. III) 1 (1953) 131 ; Ducastelle, F., Chaudron, R. and Costa, P., J. Physique 31 (1970) 57.

[17] Wohlfarth, E. P., Acta Metall. 4 (1956) 225.

[18] Gupta, M., Solid State Commun. 29 (1979) 47.

[19] Rhodes, P. and Wohlfarth, E. P., Proc. R. Soc. A 273 (1963) 247 ; Wohlfarth, E. P., J. Magn. Mag. Mat. 7 (1978) 113.

[20] Wu, M. K., Chu, C. W., Smith, J. L., Giorgi, A. L., Huang, C. Y., Matthias, B. T. and Wang, F. E., Solid State Commun. 34 (1980) 507.

[21] Edwards, D. M., Electrons in disordered metals (Plenum) 1979 , p. 355.

[22] ACker, F., Fisk, Z., Smith, J. L. and Huang, C. Y., J. Magn. Mag. Mat. (1981), to be published. 